\title{
Alkaline treatment and thermal properties of Napier grass fibres
}

\author{
M. Haameem J.A. ${ }^{1}$, M.S. Abdul Majid ${ }^{1}$, M. Afendi ${ }^{1}$, Haslan M. ${ }^{2}$, I. Fahmi ${ }^{1}$ \\ ${ }^{1}$ School of Mechatronic Engineering, Universiti Malaysia Perlis, Arau, Malaysia \\ ${ }^{2}$ Advanced Material Research Centre (AMREC), SIRIM Berhad, Kulim, Malaysia. \\ Email: mhaameem@gmail.com; shukry@unimap.edu.my
}

\begin{abstract}
This paper presents an overview of a natural fibre, namely Pennisetum purpureum, which is commonly known as Napier grass. This paper's intention is to analyse Napier grass fibre to assess the effect of alkaline treatment on the tensile properties, thermal stability, and morphology of the fibres. These fibres were extracted by a water retting process from the internodes of Napier stems. The fibres were later subjected to alkaline treatments with $\mathrm{NaOH}$ at 5, 10, 15 and $20 \%$ concentrations for a period of $24 \mathrm{~h}$ at $25^{\circ} \mathrm{C}$ (RT). The tensile strength, thermal stability and crystallinity of the fibres were seen to upsurge upon conducting the alkaline treatments. Thus, the experimental results demonstrate that the $10 \% \mathrm{NaOH}$ concentration has the strongest tensile test compared to untreated Napier grass fibre. The surfaces of the fibres after the treatment were observed with a scanning electron microscope (SEM), TM-3000. SEM investigation showed that the surfaces of the fibres become rougher after $\mathrm{NaOH}$ treatment. Moreover, from XRD, the amount of crystallinity is also higher in the $10 \%$ alkaline treated fibres, and DSC thermograms proved that they have better thermal stability. From this study, Napier grass fibres show potential to be used as reinforcing fibres in composite structures.
\end{abstract}

Keywords: Napier grass fibres; tensile; alkaline treatment; thermal properties; electron microscopy.

\section{INTRODUCTION}

Glass fibres are the most widely used to make reinforcement due to their low cost compared to carbon and aramid. However, these glass fibres have a significant environmental impact, meaning that they have serious drawbacks [1]. Presently, extensive research is being conducted to determine the potential of natural fibres in non-structural applications. Thus, it is fascinating to study the thermal stability of these natural fibres before applying them as reinforcement in thermal applications [2]. The physical properties of natural fibres are primarily classified by their chemical and physical composition, such as the structure of the fibres and cellulose content and by the degree of polymerization [3, 4]. Napier grass also contains hemicelluloses, cellulose and lignin. This content of hemicellulose and cellulose shows that this plant can be an alternative fibre to produce paper, as proposed by Daud et al. [5]. The biggest problem in the use of natural fibre composites is the fibre-matrix adhesion. The function of the matrix is to transfer the load to the fibres. This can be accomplished if a good adhesion bonding between the matrix and the fibres is ensured. Insufficient adhesion bonding at the interface means that their advantages cannot be fully utilised and that they are exposed to environmental attack [6]. Poor adhesion between hydrophobic polymers and hydrophilic fibres implies poor properties for the composites [7]. Nevertheless, these properties can 
be improved by physical and chemical treatments. Alkaline treatment is one of the most widely applied chemical methods to remove a certain portion of the lignin, wax and oils that cover the exterior surface of the fibre cell wall. The important alteration achieved with alkaline treatment is to breach the hydrogen bonding in the network structure, such that the surface roughness is increased, thereby enabling good bondings to be achieved $[8,9]$.

On the other hand, ligno-cellulosic fibres are submitted to intense heat during fabrication. Therefore, thermal analysis study is necessary to determine the influence of the treatments on the fibres to observe the degradation behaviour. Geethamma et al. [9] used 5\% $\mathrm{NaOH}$ to remove surface impurities on oil palm fibres. Obi Reddy et al. [10] analysed and characterised Indian-grown Napier grass fibre when untreated, 2 and 5\% $\mathrm{NaOH}$ treated and found that the $\mathrm{NaOH}$ treatment eliminated the amorphous hemicellulose component of the fibres. Joseph et al. [11] reported in their studies that the mechanical tensile strength for 5,10 , and $15 \% \mathrm{NaOH}$ treatment was $9.95 \mathrm{MPa}, 9.61 \mathrm{MPa}$ and $8.86 \mathrm{MPa}$ respectively for oil palm fibre. Joseph et al. [12] also concluded that the modification can either increase or decrease the strength of the fibres, thus what occurs structurally is of great importance. Valadez and colleagues [13] carried out research regarding kenaf bonding with resins. They concluded that alkaline treatment has two effects on the fibre, increasing both the surface roughness and the cellulose on the fibre surface. Both these effects can yield a better mechanical interlocking between the fibres. Recently, work conducted by Haameem et al. [14] showed that $10 \% \mathrm{NaOH}$ treatment of Napier grass fibre demonstrates the highest tensile strength. Furthermore, the SEM observation suggests that $\mathrm{NaOH}$ treatment causes the fibres to become rougher, thus leading to increased friction in the matrix material. The aim of this paper is to investigate single fibre testing and the effects of different $\mathrm{NaOH}$ concentrations on Napier fibres. Furthermore, the thermal analysis is also studied by using digital scanning calorimetry (DSC) and thermogravimetry (TGA) to obtain their glass transition and melting temperature. X-ray diffraction (XRD) was also applied to determine the degree of crystallinity of the untreated and treated fibres.

\section{Fibre Preparation}

\section{MATERIALS AND METHOD}

Three to six month old Napier grass stems were collected from a farm in the Northern Malaysia region, Bukit Kayu Hitam, Kedah. This farm grows Napier grass to feed cattle. The Napier grass is then conventionally subjected to a water retting process to extract the fibres from grass its internodes. The stems are chopped at the internodes and crushed with a mallet, as presented in Figure 1(a). This process is to facilitate the process of separating the fibre strands. The chopped and crushed stems are then soaked in a tank as shown in Figure 1(b). The stems are left to soak for around 3 to 4 weeks. Water retting enhances the production of more identical and high-quality fibres. After soaking for 3 to 4 weeks, the stems were a processed in a roll-out machine to separate the fibres, as displayed in Figure 1(c). The separated fibres were washed carefully using running tap water to remove any impurities. Finally, the Napier grass fibre was sun-dried for a few days to remove the maximum moisture from the fibre, as shown in Figure 1(d). The fibres are weighed daily to ensure that they have completely dried and achieve a homogeneous weight of dried fibre. Colour change within the fibres also indicates the loss of moisture. 


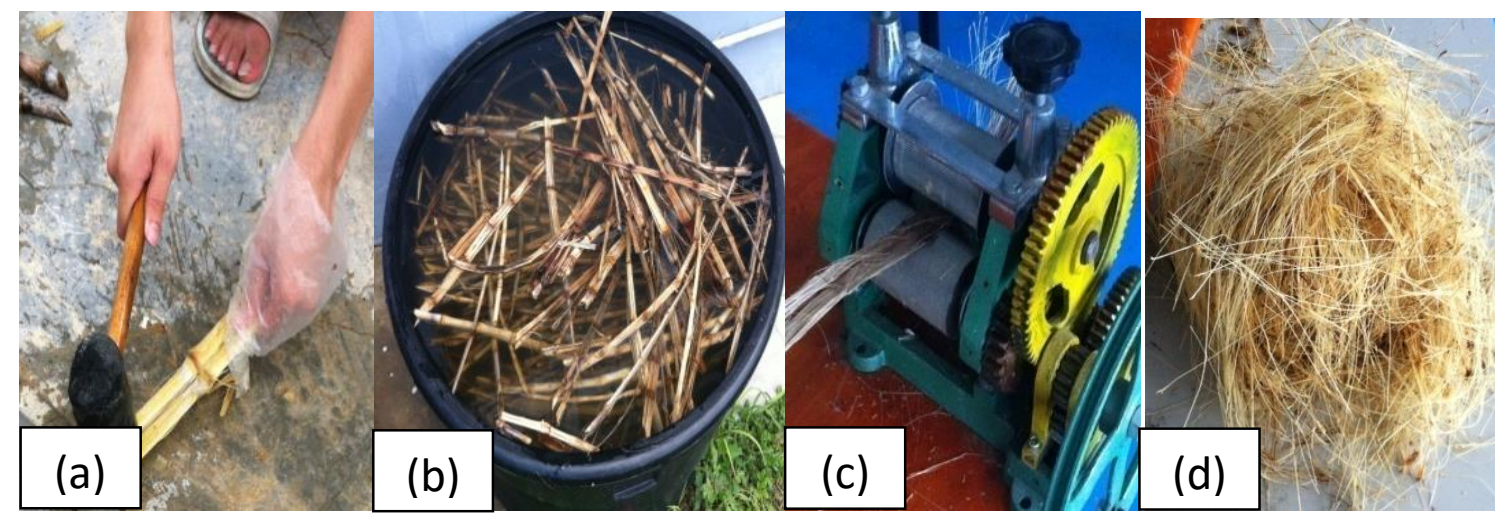

Figure 1. (a) Stem is beaten with a mallet, (b) soaked stems, (c) roll-out machine to separate fibres, and (d) extracted Napier grass fibre to be dried.

\section{Alkaline Treatment of Napier Grass Fibres}

The sun-dried fibres were then oven-dried to remove the moisture further within the fibres. The fibres were soaked in a solution of 5, 10, 15 and $20 \%$ sodium hydroxide $(\mathrm{NaOH})$ at $28^{\circ} \mathrm{C}$ (room temperature) as shown in Figure 2(a). The fibre to $\mathrm{NaOH}$ solution ratio was kept at 1:10. The fibres were kept immersed in the $\mathrm{NaOH}$ solution for 24 hours to remove the cellulose [10]. After the soaking period, the fibres were repeatedly washed with distilled water as displayed in Figure 2(b). After washing carefully with distilled water, the fibres were sun-dried again for one week.

\section{Single Fibre Tensile Test}

The single fibre tensile test was determined using an INSTRON micro tester at a crosshead speed of $1 \mathrm{~mm} / \mathrm{min}$ as stated in ASTM D3392. The gauge length was specified at $50 \mathrm{~mm}$. In this test, Napier grass lengths of more than $100 \mathrm{~mm}$ were used and tabbing was done as shown in Figure 2(c). The tabbing was attached to the samples to make sure that the fibre end did not slip at the gripper during testing. A total of twenty samples were tested for this work and the average values of the tensile strength, tensile modulus, breaking tenacity, linear density and tensile strength were calculated. A digital optical microscope was used to measure the fibre diameters, as shown in Figure 2(d).

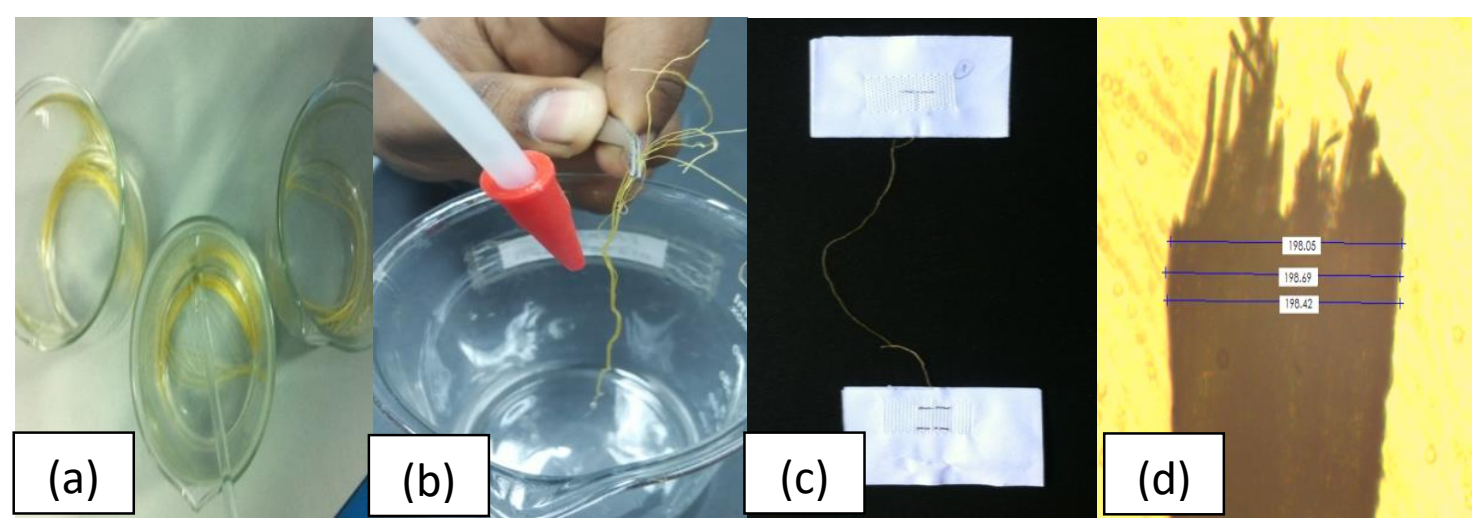

Figure 2. (a) Immersed fibre in $\mathrm{NaOH}$ solution, (b) washing fibre using distilled water, (c) fibre tabbing and (d) microscope measurements of fibre diameter. 


\section{X-ray Diffraction (XRD) Analysis}

The X-ray diffraction (XRD) spectra of the Napier grass fibres were recorded on a Brucker D2 Phaser as shown in Figure 3(a). The XRD is a type of X-ray powder diffraction. The Xray tube is the copper $(\mathrm{Cu})$ type and generates at $30 \mathrm{kV}$ and $10 \mathrm{~mA}$. The diffraction machine was operated at a scan speed of $4 \% \mathrm{~min}$ in steps of $0.05^{\circ}$. The samples were scanned from the range $2 \theta$, varying from $5^{\circ}$ to $45^{\circ}$ for untreated and treated fibres.

\section{Thermogravimetric analysis (TGA)}

The samples used for this thermogravimetric analysis were extracted Napier grass fibre weighing $0.471 \mathrm{mg}$. After weighing, the samples were sun-dried in order to maximise moisture loss. The analyses were done at a heating rate of $20^{\circ} \mathrm{C} / \mathrm{min}$ and inert nitrogen gas was used as the atmosphere.

\section{Digital Scanning Calorimetry (DSC) Test}

The DSC machine was used to find the glass transition temperature (Tg) and melting temperature $(\mathrm{Tm})$. The rate of heating was maintained at $10^{\circ} \mathrm{C} / \mathrm{min}$ and data was taken until $350^{\circ} \mathrm{C}$.

\section{Study of morphology}

The morphology of the Napier grass fibre was analysed using a scanning electron microscope (SEM), TM-3000 with a magnified resolution of 100-200x.

\section{RESULTS AND DISCUSSION}

\section{Single Fibre Tensile Test}

The single fibre tensile test results are presented in Figure 3. From this, it is clearly seen that the highest strength obtained is for $10 \%$ alkaline treated Napier grass fibre with 106.2 $\mathrm{MPa}$. The second highest is for $15 \%$, followed by $5 \%$ and $20 \%$ alkaline treated Napier grass fibre. The lowest strength is $12.4 \mathrm{MPa}$ recorded for untreated Napier grass fibre. This indicates that the $10 \%$ alkaline treated fibre had increased almost $85 \%$ from the untreated fibre. The alkaline treatment causes fibrillation, which is a process that causes the fibre bundle to break into smaller bundles. Smaller bundles help to distribute the load applied throughout the fibres $[14,15]$. The most remarkable reduction of strength is seen at $15 \%$ and $20 \%$ alkaline treated; this is because at higher percentage concentrations, excess de-lignification of the Napier grass fibre occurs, weakening and thus damaging the fibres. Ridzuan et al. reported a similar observation, where the main structural components of the fibre were attacked, resulting in the formation of more grooves on the surface of the fibre. Consequently, this leads to further weakening of the fibre strength, resulting in a decrease in the ultimate tensile stress [16].

Table 1 summarises the single fibre parameters, comparing untreated and treated Napier grass fibre. The mass of the Napier grass fibre varies from $0.004 \mathrm{~g}$ to $0.0078 \mathrm{~g}$. The diameter of the fibre varies from $154 \mu \mathrm{m}$ to $259 \mu \mathrm{m}$. The table shows that the unit break is highest for $10 \%$ treated fibres, which also have the lowest linear density among other fibre conditions. The unit break is breaking tenacity over linear density. Linear density is a measure of mass per unit length. Thus, breaking tenacity is directly proportional to linear density. Therefore, the lower the linear density, the higher the breaking tenacity. The fibre diameter varied in the range $\sim 150-250 \mu \mathrm{m}$. The results show that the $10 \% \mathrm{NaOH}$-treated fibre exhibited the highest breaking tenacity of $>7000 \mathrm{~N} / \mathrm{tex}$. The untreated fibre exhibited the lowest breaking tenacity of $462 \mathrm{~N} / \mathrm{tex}$. The fibres were enhanced by the alkaline 
treatment because it increased their surface roughness and decreased their moisture content, particularly for the $10 \% \mathrm{NaOH}$-treated specimens. Subsequently, the breaking tenacity decreased from $7093 \mathrm{~N} / \mathrm{Tex}$ to $6480 \mathrm{~N} / \mathrm{Tex}$ and further reduced to $2117 \mathrm{~N} / \mathrm{Tex}$ for the $10 \%, 15 \%$, and $20 \% \mathrm{NaOH}$-treated samples, respectively.

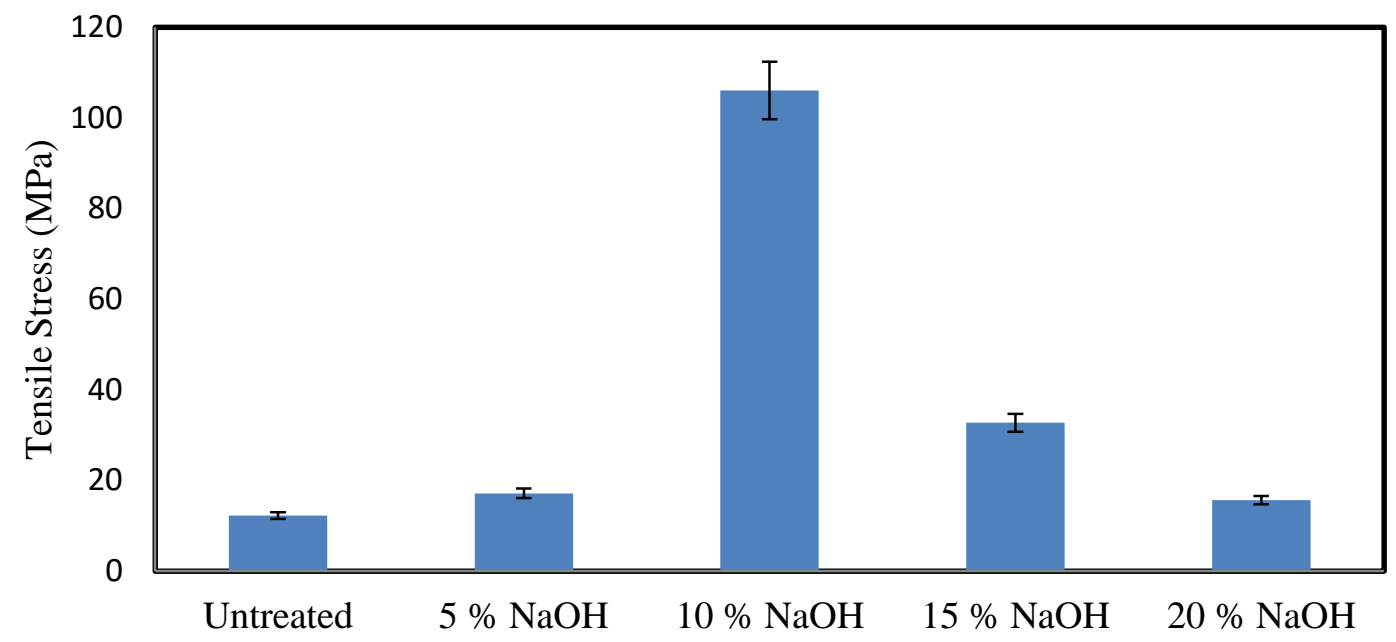

Figure 3. Tensile stress $(\mathrm{MPa})$ versus against different $\mathrm{NaOH}$ percentage treatments.

Table 1. Single fibre average mass, length, diameter, area, linear density and unit break.

\begin{tabular}{lccccc}
\hline \multirow{2}{*}{ Sample type } & $0 \%$ & $5 \%$ & $10 \%$ & $15 \%$ & $20 \%$ \\
& Untreated & $\mathrm{NaOH}$ & $\mathrm{NaOH}$ & $\mathrm{NaOH}$ & $\mathrm{NaOH}$ \\
\hline \hline Average mass $(\mathrm{g})$ & 0.0041 & 0.0078 & 0.004 & 0.0041 & 0.0053 \\
Average length $(\mathrm{mm})$ & 121.5 & 130.7 & 140.2 & 135.1 & 140.9 \\
Average diameter $(\mu \mathrm{m})$ & 199 & 259 & 154 & 192 & 249 \\
Average area $\left(\mathrm{mm}^{2}\right)$ & 0.030 & 0.051 & 0.020 & 0.030 & 0.050 \\
Linear density $(\mathrm{kg} / \mathrm{m})$ & 0.000332 & 0.000589 & 0.00028 & 0.000298 & 0.000371 \\
Unit break $(\mathrm{N} / \mathrm{Tex})$ & 462.02 & 1621.61 & 7093.20 & 6479.57 & 2117.22 \\
\hline
\end{tabular}

\section{X-ray Diffraction (XRD) Analysis}

XRD analysis was conducted to investigate the crystallinity of the Napier grass fibres. XRD diffractograms are given in Figure 4 and the $\%$ crystallinity was calculated according to the Segal empirical method as described in Equation (1):

$$
\% \mathrm{Ic}=\frac{I(002)-I(\mathrm{am})}{I(\mathrm{am})} \times 100
$$

where $I_{(002)}$ is the peak intensity counter reading at a $2 \theta$ angle close to $22^{\circ}$ representing crystalline material and $\mathrm{I}_{(\mathrm{am})}$ is the counter reading at a $2 \theta$ angle close to $16^{\circ}$ representing amorphous material in the samples [17]. Therefore, the degree of crystallinity for the untreated fibres is $25.5 \%$ and for the $10 \%$ alkaline treated is $39.5 \%$. This shows that the percentage crystallinity index of alkaline treated Napier grass fibres is $14 \%$ higher than that of the untreated Napier grass fibres. This increase in percentage crystallinity index indicates the improvement in the restructure of cellulose, and finally contributes to enhancing the tensile strength of the Napier grass fibres because of the realignment of 
cellulose molecules [17, 18]. Recently, Zhijia and Benhua found that the relative crystallinity of untreated bamboo and $\mathrm{NaOH}$ treated bamboo samples was $44.4 \%$ and $55.2 \%$. The crystallinity is relatively higher because bamboo is $70 \%$ made up of cellulosic materials [19]. Moreover, alkaline treated fibres lose some of their amorphous constituents after treatment, which results in the treated fibres appearing to be more crystalline than the untreated ones [6].

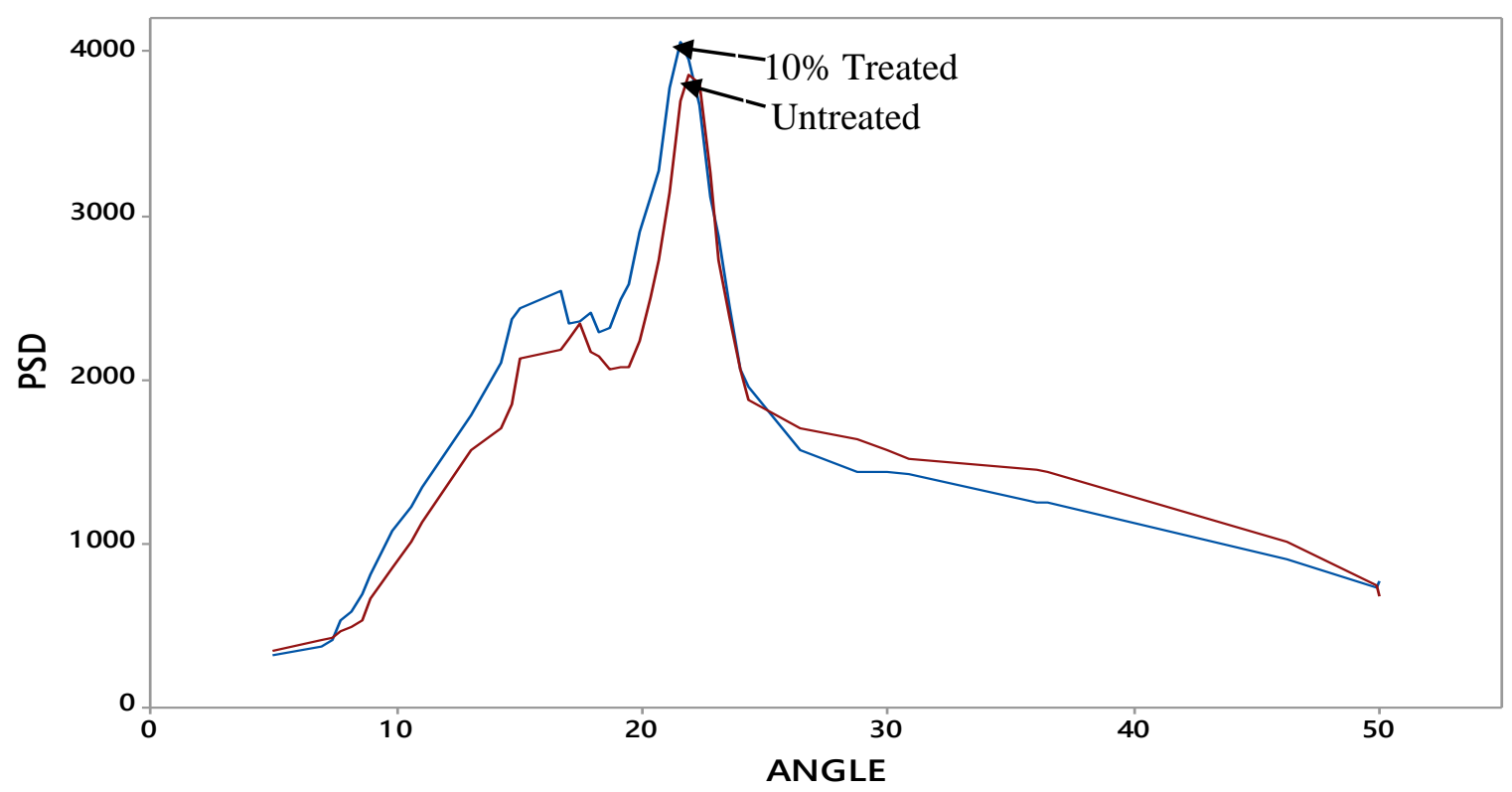

Figure 4. X-ray diffractograms of untreated and $10 \%$ alkaline treated Napier grass fibres.

\section{Thermogravimetric Analysis (TGA)}

The TGA thermogram is presented in Figure 5. The thermogram indicates that it takes a few stages of degradation for the untreated Napier grass fibre. Due to differences in the chemical structure, the components of the fibres usually decompose at different temperatures [20]. A slight weight drop was seen at $100^{\circ} \mathrm{C}$. The weight is less than $10 \%$, corresponding to the moisture depleted in the fibres. The first stage that takes place in the range of $230-300^{\circ} \mathrm{C}$ is associated with depolymerization of hemicelluloses and some of the lignin. The second stage occurs at $300-400^{\circ} \mathrm{C}$ and corresponds to the degradation of most of the alpha celluloses and lignin. This shows that the lignin is the hardest part to decompose as it requires high temperatures, as concluded earlier by Kabir et al [21]. Its decomposition extends over the entire temperature range. Based on the thermogram, the initial, 25\%, 50\% and final degradation calculated thus are summarised in Table 2 . The initial and the final degradation occur at $250^{\circ} \mathrm{C}$ and $356^{\circ} \mathrm{C}$ respectively [8].

\section{Digital Scanning Calorimetry (DSC) Test}

Thermal transitions were observed from the DSC thermograms, as presented in Figure 6. The phases that can be seen in these thermograms are the glass transition, $\mathrm{Tg}$. At the $\mathrm{Tg}$, the Napier grass fibre molecules possessed enough energy to overcome the intermolecular forces and have a degree of freedom. The Napier grass fibre now becomes softer and flexible. The $\mathrm{Tg}$ for untreated fibre is around $40^{\circ} \mathrm{C}$ and $58^{\circ} \mathrm{C}$ for $10 \%$ alkaline treated fibre. Treated fibre shows a higher Tg compared to untreated fibre because of the hemicelluloses and part of the lignin that is removed through alkalization. Therefore, the 
thermal stability of the treated fibre increases compared to untreated fibres [21]. It was observed that $10 \% \mathrm{NaOH}$ treated fibre showed higher thermal stability than other treated fibres, which indicates the improved hydrophobic nature of the fibre. It becomes more hydrophobic because the treated fibre has lost the hemicelluloses and a part of the lignin which contain moisture [13].

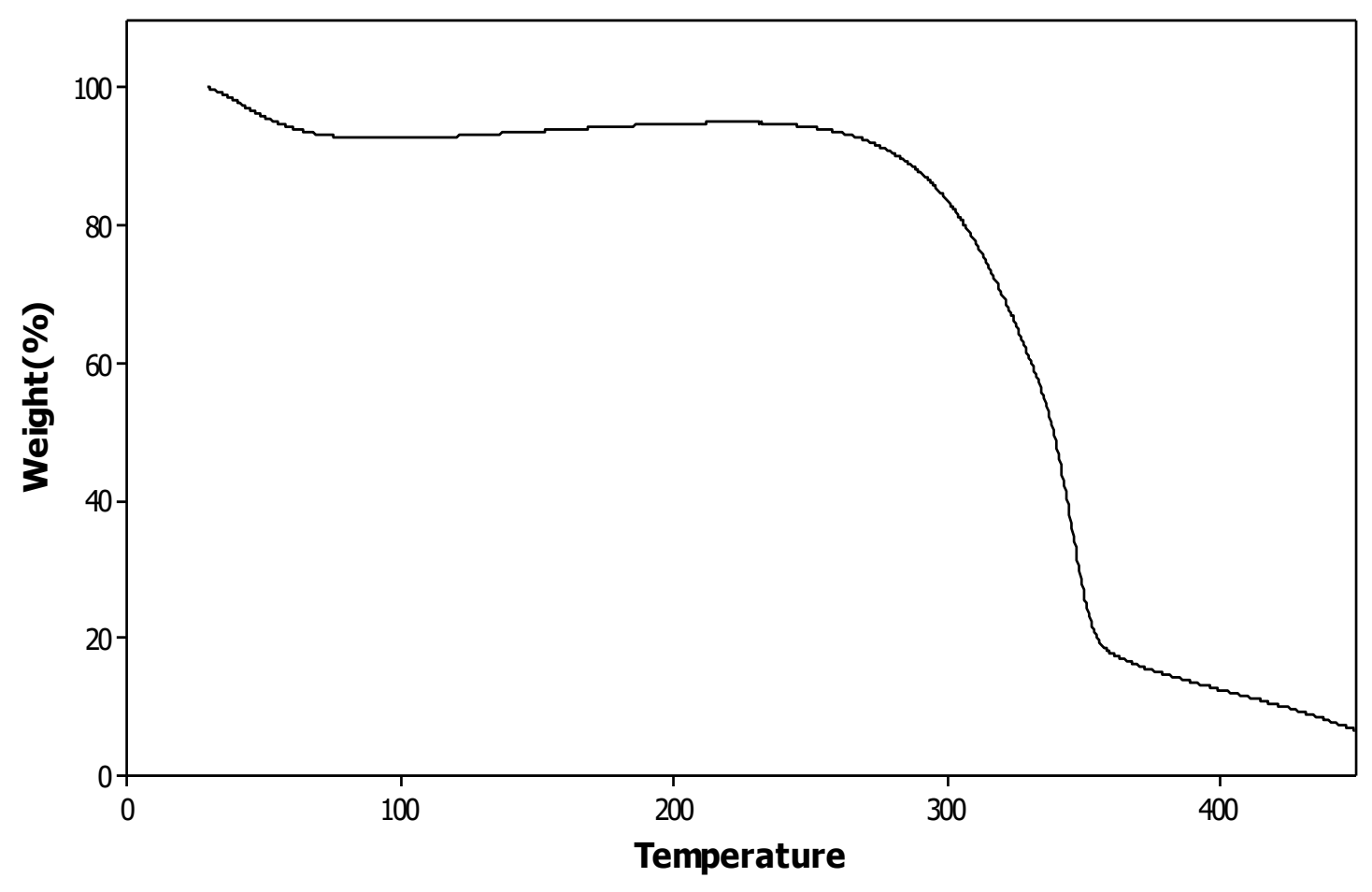

Figure 5. TGA thermogram of untreated Napier grass fibres.

Table 2. Thermal degradation parameters for untreated Napier grass fibres.

\begin{tabular}{cc}
\hline Degradation parameter & Temperature $\left({ }^{\circ} \mathrm{C}\right)$ \\
\hline \hline Initial degradation & 250 \\
$25 \%$ degradation & 314 \\
$50 \%$ degradation & 339 \\
Final degradation & 356 \\
\hline
\end{tabular}

\section{Morphology Study}

Morphology examinations were conducted on the untreated and alkalized fibres to examine the changes that occurred before and after treatment. The SEM micrograph of the untreated Napier fibre bundles in Figure 7(a) shows the presence of wax, oil and surface impurities. Waxes and oils provide a shielding layer to the surface of the fibres [22]. The 10\% alkaline treated Napier grass fibre in Figure 7(b) shows a rougher surface. The surface of the $10 \%$ alkaline treated fibre appears to be quite clean of waxes and oil, but in actuality is roughened by the chemical treatment. Such rough surfaces hopefully promote good interfacial bonding between fibres and the resin matrices, if the fibres are used as reinforcement [21, 23]. Fibrillation was also observed in the $10 \%$ alkaline treated fibre, increasing the numbers of fibrils to transfer the load applied amongst them $[14,15]$. 


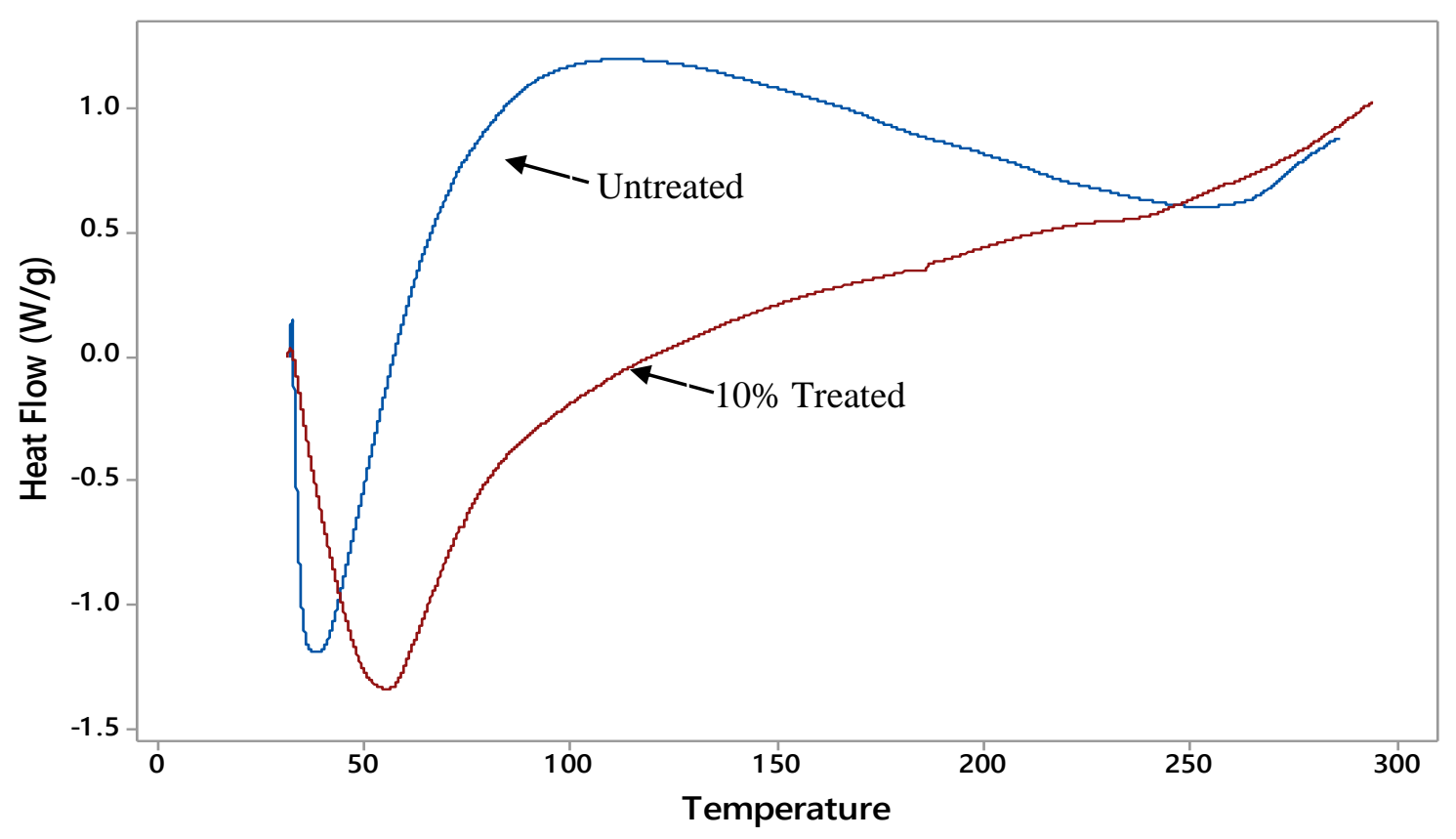

Figure 6. DSC thermogram of untreated Napier grass fibres.

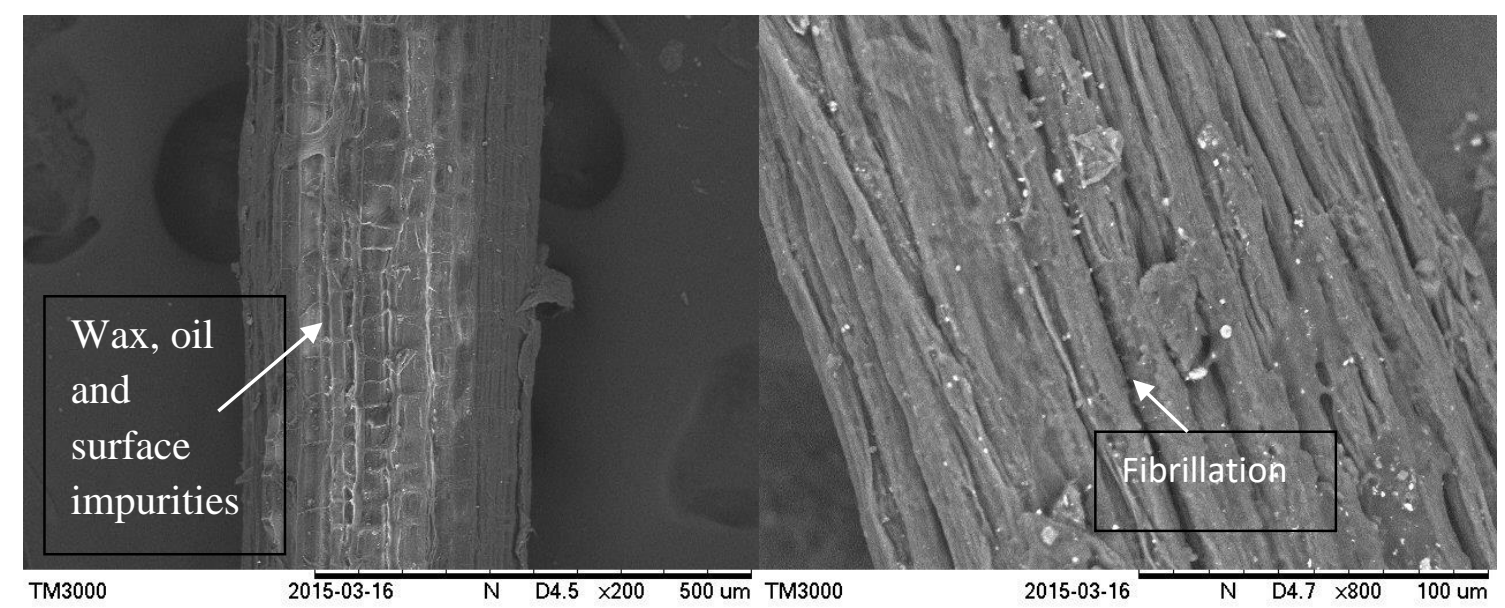

Figure 7. SEM of Napier grass fibres: (a) untreated and (b) $10 \%$ alkaline treated.

\section{CONCLUSIONS}

The Napier grass fibres were treated with different percentage alkaline concentrations. It can be seen that $10 \%$ alkaline treatment resulted in the highest tensile strength compared to untreated and other percentage concentrations. Moreover, from XRD analysis, the percentage crystallinity of treated Napier grass fibres is found to be higher than when untreated. The DSC test proves that the thermal stability increases for the $10 \%$ alkaline treated fibres as the glass transition value is higher by $18 \%$. The SEM of the untreated and $10 \%$ alkaline treated fibres revealed that the fibre becomes fibrils, which helps the load transfer in the fibres. From this morphology it was also concluded that the fibres become roughened upon treatment, and unwanted substances on the fibres are eliminated. It is recommended that further research on Napier grass fibre should examine different 
types of chemical treatments. The study further supported the feasibility of exploiting Napier grass fibres as reinforcing materials in polymer composites.

\section{ACKNOWLEDGEMENTS}

The authors of this paper would like to thank Universiti Malaysia Perlis (UniMAP) for providing laboratory equipment and facilities for conducting this research.

\section{REFERENCES}

[1] Wambua P, Ivens J, Verpoest I. Natural fibres: can they replace glass in fibre reinforced plastics? Composites Science and Technology. 2003;63:1259-64.

[2] Joshi SV, Drzal LT, Mohanty AK, Arora S. Are natural fiber composites environmentally superior to glass fiber reinforced composites? Composites Part A: Applied Science and Manufacturing. 2004;35:371-6.

[3] Bledzki AK, Gassan J. Composites reinforced with cellulose based fibres. Progress in Polymer Science. 1999;24:221-74.

[4] Rejab MRM, Noor MM, Daud R, Kadirgama K, Sani MSM. Effect of adverse environment on buckling of composite laminates. Malaysian Technical Universities Conference on Engineering and Technology. Kuantan, Pahang, Malaysia.2009.

[5] Daud Z, Mohd Hatta MZ, Mohd Kassim AS, A. AM. Suitability of Malaysia's pineapple leaf and Napier grass as a fiber substitution for paper making industry. Enginering Conference Energy Environment2013. p. 1-4.

[6] Sapuan MM, Hamdan MM, Bachtiar HD. Flexural properties of alkaline treated sugar palm fibre reinforced epoxy composites. International Journal of Automotive \& Mechanical Engineering 2010;1:12.

[7] Joseph PV, Rabello MS, Mattoso LHC, Joseph K, Thomas S. Environmental effects on the degradation behaviour of sisal fibre reinforced polypropylene composites. Compos Sci Technol. 2002;62:1357-72.

[8] John M, Anandjiwala R. Recent developments in chemical modification and characterization of natural fiber reinforced composites. Polymer Composites. 2008;29:11.

[9] Geethamma VG, Thomas Mathew K, Lakshminarayanan R, Thomas S. Composite of short coir fibres and natural rubber: effect of chemical modification, loading and orientation of fibre. Polymer. 1998;39:1483-91.

[10] Reddy KO, Maheswari CU, Reddy DJP, Rajulu AV. Thermal properties of Napier grass fibers. Materials Letters. 2009;63:2390-2.

[11] Sreekala MS, Kumaran MG, Joseph S, Jacob M, Thomas S. Oil palm fibre reinforced phenol formaldehyde composites: influence of fibre surface modifications on the mechanical performance. Applied Composite Materials. 2000;7:295-329.

[12] Joseph PV, Joseph K, Thomas S. Short sisal fiber reinforced polypropylene composites: the role of interface modification on ultimate properties. Composite Interfaces. 2002;9:171-205.

[13] Valadez-Gonzalez A, Cervantes-Uc JM, Olayo R, Herrera-Franco PJ. Effect of fiber surface treatment on the fiber-matrix bond strength of natural fiber reinforced composites. Composites Part B: Engineering. 1999;30:309-20. 
[14] Haameem J, Abdul Majid M, Haslan M, Afendi M, Helmi E, Idris F. Effects of alkaline treatments on the tensile strength of Napier grass fibres. Applied Mechanics and Materials. 2014;695:4.

[15] Wong KJ, Zahi S, Low KO, Lim CC. Fracture characterisation of short bamboo fibre reinforced polyester composites. Materials \& Design. 2010;31:4147-54.

[16] Ridzuan MJM, Abdul Majid MS, Afendi M, Aqmariah Kanafiah SN, Zahri JM, Gibson AG. Characterisation of natural cellulosic fibre from Pennisetum purpureum stem as potential reinforcement of polymer composites. Materials \& Design. 2016;89:839-47.

[17] Groeneveld RA, Meeden G. Measuring skewness and kurtosis. The Statistician. 1984:391-9.

[18] Chai T, Ding J, Wu F. Hybrid intelligent control for optimal operation of shaft furnace roasting process. Control Engineering Practice. 2011;19:264-75.

[19] Li X, Tabil LG, Panigrahi S. Chemical Treatments of Natural Fiber for Use in Natural Fiber-Reinforced Composites: A Review. Journal of Polymers and the Environment. 2007;15:25-33.

[20] Monteiro SN, Calado V, Rodriguez RJS, Margem FM. Thermogravimetric Stability of Polymer Composites Reinforced with Less Common Lignocellulosic Fibers - an Overview. Journal of Materials Research and Technology. 2012;1:117-26.

[21] Kabir MM, Wang H, Lau KT, Cardona F. Chemical treatments on plant-based natural fibre reinforced polymer composites: An overview. Composites Part B: Engineering. 2012;43:2883-92.

[22] Haameem JAM, Abdul Majid MS, Afendi M, Marzuki HFA, Fahmi I, Gibson AG. Mechanical properties of Napier grass fibre/polyester composites. Composite Structures. 2016;136:1-10.

[23] Akhtar MN, Gaaz TS, Sulong AB, Raza R. Morphology and tensile properties of thermoplastic polyurethane-halloysite nanotube nanocomposites. International Journal of Automotive \& Mechanical Engineering. 2015;12:13. 